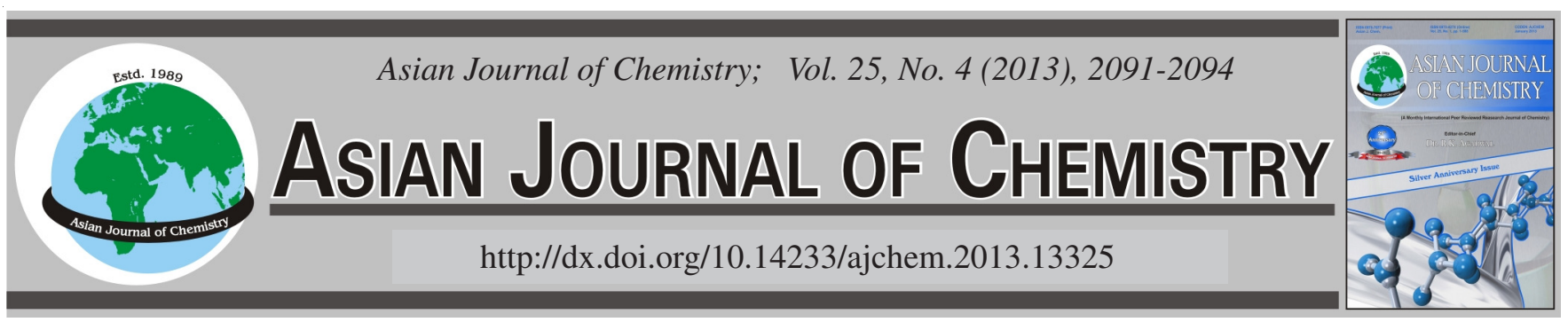

\title{
A Comparative Study of Tianzhu White Yak's Blood Copper with Yak's in Other Sites of Tibetan Plateau
}

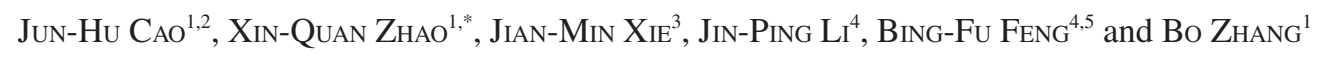

${ }^{1}$ Northwest Institute of Plateau Biology, the Chinese Academy of Sciences, Key Laboratory of Adaptation and Evolution of Plateau Bioata, Xining 810000, P.R. China

${ }^{2}$ Graduate University of Chinese Academy of Sciences, Beijing 100049, P.R. China

${ }^{3}$ Qinghai Provincial People's Hospital, Xining 810000, P.R. China

${ }^{4}$ Qinghai Normal University, Xining 810000 , P.R. China

${ }^{5}$ Qinghai Animal husbandry \& Veterinary Medicine Vocational Technical College, Xining 810000, P.R. China

*Corresponding author: Tel: +86971 6143618; E-mail: caojunhu05@yahoo.com

(Received: 24 December 2011;

Accepted: 15 October 2012)

AJC-12287

\begin{abstract}
One hundred and ten individually male yaks which lived in eleven sites around Qinghai Tibetan Altiplano were used to determine the whole blood concentrations of trace elements $(\mathrm{Cu}, \mathrm{Cr}, \mathrm{Mn})$. Yak were stratified by regions to 11 sites. The eleven areas or treatments is Tibet (including Yadong, Rikeze, Dangxiong, Shannan), Qinghai (including Yushu, Maqin, Dari), Gansu (including Tianzhu and Sunan), Xinjiang (including Heshuo, Yiwu), respectively. The date of experiment showed that the trace elements concentrations of whole blood range were copper $0.585-0.755 \mu \mathrm{g} / \mathrm{mg}$, chromium $17.315-20.877 \mu \mathrm{g} / \mathrm{mg}$ and manganese $0.216-0.264 \mu \mathrm{g} / \mathrm{mg}$, respectively. Results indicate that the copper concentrations in whole blood of white yaks lived in Tanzhu were specific lower than they were on whole blood of yak which lived in other areas else. Analysis of correlation between copper and other trace elements in plasma from yaks also found a significant positive correlations. The correlations between plasma copper, chromium and manganese were $\mathrm{r}=0.282$ and $0.254(p<0.01)$, respectively.
\end{abstract}

Key Words: Yak, White yak, Plasma, Concentrations, Trace element, Melanin, Copper.

\section{INTRODUCTION}

The importance of trace element for animal's biochemical and physiological changes have been confirmed in a large numbers of correlative studying. Research in ewes has demonstrated that copper deficiency could reduce appetite and growth, as well as impairment of several metabolic enzymes ${ }^{1}$. Low copper and zinc concentration in blood have also been associated with skin lesions ${ }^{2}$. And studies of smelter smoke syndrome in farm animals suggest that manganese deficiency may be more susceptible than any other facts ${ }^{3}$. Besides the clinical symptoms we mentioned above, aspects of the immune system that have been reported to be impaired by trace element deficiency include cell mediated and hormonal immunity ${ }^{4}$, superoxide dismutase activity ${ }^{5-7}$, T cell proliferation, cytokine production and antibody production ${ }^{8}$. Furthermore, genetic and environmental factors have been reported to impact animal's ability to respond immunologically to an antigen ${ }^{8}$. Proper nutritional management of feedlot cattle can help reduce the impact of environmental factors by enhancing an animal's immune system via vaccination and proper nutrition ${ }^{9}$. Trace element is commonly supplemented to most feedlot diets in the world, both as inorganic and organic sources.

The yak (Bosgrunniens) is apeculiar domestic animal species in alpine meadow of Tibet plateau and adapts to the ecosystem in Himalayan Mountains and Qinghai-Tibet Plateau. It was firstly domesticated about 10,000 years ago in China ${ }^{10}$ where there are now more than 13 million yaks, making up > $90 \%$ of the world yaks population. And yaks in Sitsang, Qinghai, Gansu, Xinjiang provinces account for $76 \%$ of the China yaks population. In the Qinghai-Tibetan Plateau, $c a$. 3000-4700 m altitude above sea level, the yak farming not only provide a critical source of animal products such as meat, milk and hides, etc., but also act as an indispensable means of transportation in this area. Although the domestic yak constitutes one of the most important domestic animal genetic resources of the regions and is very important for local economy, the productivity of the yak in Qinghai-Tibetan Plateau have been decreasing in the recent years ${ }^{11-13}$ reported that trace element deficiencies are common in ruminants, especially extensively grazed animals with access only to grass and other naturally 
occurring plant material as their staple diet ${ }^{14}$. And Shen XiaoYun ${ }^{15}$ find that ailments characterized by pica, emaciation, dyskinesia and anemia of yaks in the Haizi area are probably caused by a secondary copper deficiency. Wang et al. ${ }^{16}$ pointed out that many factors affect the bioavailability of dietary Zn, which leads to yak's low availability in some food systems and $\mathrm{Zn}$ nutrient deficiency. In contract, some proteins or peptides can form complexes with $\mathrm{Zn}$ and increase its absorption and bioavailability in intestinal conditions.

Since most studies have shown that trace elements deficiencies and imbalances are very important for animal's health. The objective of this study is (1): To determine trace elements deficiencies using whole blood concentrations of yaks in different areas around Qinghai-Tibetan Plateau; (2): Provide basic reference levels to help people feed yak more efficiency in race element supplement program.

\section{EXPERIMENTAL}

The study focused on 4 provinces or autonomous regions including 11 representative sites around Qinghai-Tibetan Plateau $\left(27-43^{\circ} \mathrm{N}, 83-102^{\circ} \mathrm{E}\right.$, Fig. 1). The four provinces and autonomous regions are Sitsang (including Dangxiong site in the middle of Sitsang, Rikezesite in southwest of Sitsang and the infall of Brahmaputra river and it's main branch nianchurive, Yadongsite in south of Himalayas and Shannansite in south foot of the Tanggula Mountains and Kailas Range), Qinghai (including Yushu site, Maqinsite and Darisite), Gansu (including Tianzhu sitethe east end of the Ch'i-lien Mountainsand Sunansite the north foot of the Ch'i-lien Mountains) and Xinjiang (including Yiwu site inthe northeast foot of the tianshan mountain and Heshuositein the south foot of the tianshan mountains). The whole sample collecting areas were $c a .30000 \mathrm{sq} \mathrm{km}$ and representedthree types of geobiology entironment of the pastoral yaks productions system available. They are Hinterland of the Qinghai-Tibetan plateau, Ch'i-lien Mountains (Sunan and Tianzhu) and the Tianshan mountains (Heshuo and Yiwu). All of the vegetation in these sites is typical alpine meadow and is dominated by Polygonum spp. and Kobresia spp. in Tianzhuand Sunansites, Elymus spp. Festuca spp. and Poapretensis spp. in Yiwu and Heshuo sites, Kobresia spp., Potentilla spp. Kobresiapygmaea spp. and Ipotentilla fruticosa spp. in Hinterland of the QinghaiTibetan plateau, respectively.

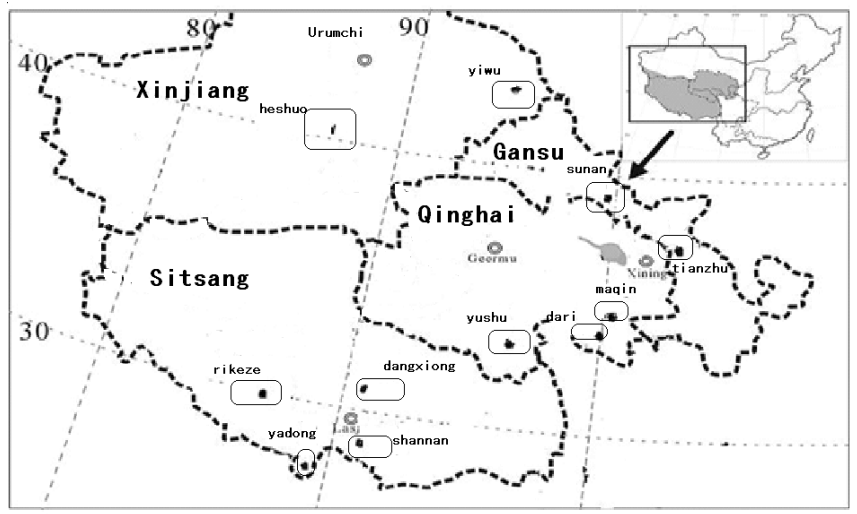

Fig. 1. Site of sampling distributing
Blood specimen collecting: Ten emasculated yaks $(30 \pm$ 6 mo of age, $90 \pm 10 \mathrm{~kg} \mathrm{BW}$ )were randomly selected for blood studying in each 11 sites during December. With the local cowhand's help, yaks were isolatedin covesor pens. A $4 \mathrm{~mL}$ blood samples were taken via jugular venepuncture in trace mineral free heparinized polyethylene tubesand analyzed for concentrations of $\mathrm{Cu}, \mathrm{Cr}$ and $\mathrm{Mn}$ in whole blood. Samples were stored on ice and immediately transported to the laboratory for processing. Prior to the initiation of this experiment, blood sampling of yaks were approved by the local governments.

Blood preparation: All of the trace elements in blood samples were pretreated and tested in Northwest A and F University. Trace elements $\mathrm{Cu}, \mathrm{Mn}$ and $\mathrm{Cr}$ in blood samples were detected by atomic absorption spectrometry in routine method and the element Cowas detected directly by graphite furnace atomic absorption spectrometry. Plasma $\mathrm{Cu}, \mathrm{Cr}$ and Mn detecting: One $\mathrm{mL}$ of $10 \%$ trichloroacetic acid (TCA) solution was added to $1 \mathrm{~mL}$ of plasma and mixed thoroughly. The mixture was placed in a $-20^{\circ} \mathrm{C}$ freezer for $30 \mathrm{~min}$ to aid in precipitation and then centrifuged at $1200 \times \mathrm{g}$ for $10 \mathrm{~min}$. The supernatant was removed and diluted in deionized $\mathrm{H}_{2} \mathrm{O}$ to fit within a linear range of a standard curve generated by linear regression of known $\mathrm{Cu}$ concentrations. Plasma samples were read at $324.7 \mathrm{~nm}$ using aflame atomic absorption spectrophotometer (Varian Model 1275; Walnut Creek, CA, USA). Concentrations of the samples were then determined by a standard curve generated by linearregression using standards of known concentrations. Other trace elements $\mathrm{Mn}, \mathrm{Cr}$ were detected in same process.

Statistical analysis: The ANOVA procedure of SPSS (17.0) for statistical analyses of the experimental data was used to analyze the distributions of the various trace elements in blood and plasma. All of the data were expressed by mean \pm $\mathrm{SD}$ and $p<0.05$ indicated that differences were significant. In order to confirm the interrelation of these three kinds of trace elements in blood of yak, two-sided test analysis of variance (pearson correlation model) was used to test the correlation coefficients in $\mathrm{Cu}, \mathrm{Mn}, \mathrm{Cr}$, simultaneity.

\section{RESULTS AND DISCUSSION}

One hundred ten blood samples of yaks were collected from 11 sites (situated in Sitsang, Qinghai, Xinjiang and Gansu, respectively) were the main regions where yak were raised. Trace elements $\mathrm{Cu}, \mathrm{Cr}$ and $\mathrm{Mn}$ in blood of yak from these 11 rural areas are summarized in Fig. 2. The plasma $\mathrm{Cu}$ in Tianzhu white yak were significantly higher than others, the concentrations of plasma trace elements $\mathrm{Cr}$ and $\mathrm{Mn}$ appeared similar among them from Fig. 2.

There was no time or treatment $x$ time interaction for these five kinds of trace elements on plasma. Therefore, overall plasma trace elements $(\mathrm{Cu}, \mathrm{Mn}$ and $\mathrm{Cr})$ concentrations for the growing phases are given in Table-1. From it we can find out that the range of these five kinds trace elements concentrations on whole blood of yaks in these eleven sites were $\mathrm{Cu}$ 0.585-0.755 $\mu \mathrm{g} / \mathrm{mg}, \mathrm{Mn} 0.216-0.264 \mu \mathrm{g} / \mathrm{mg}, \mathrm{Cr} 17.315-20.877$ $\mu \mathrm{g} / \mathrm{mg}$, respectively. 

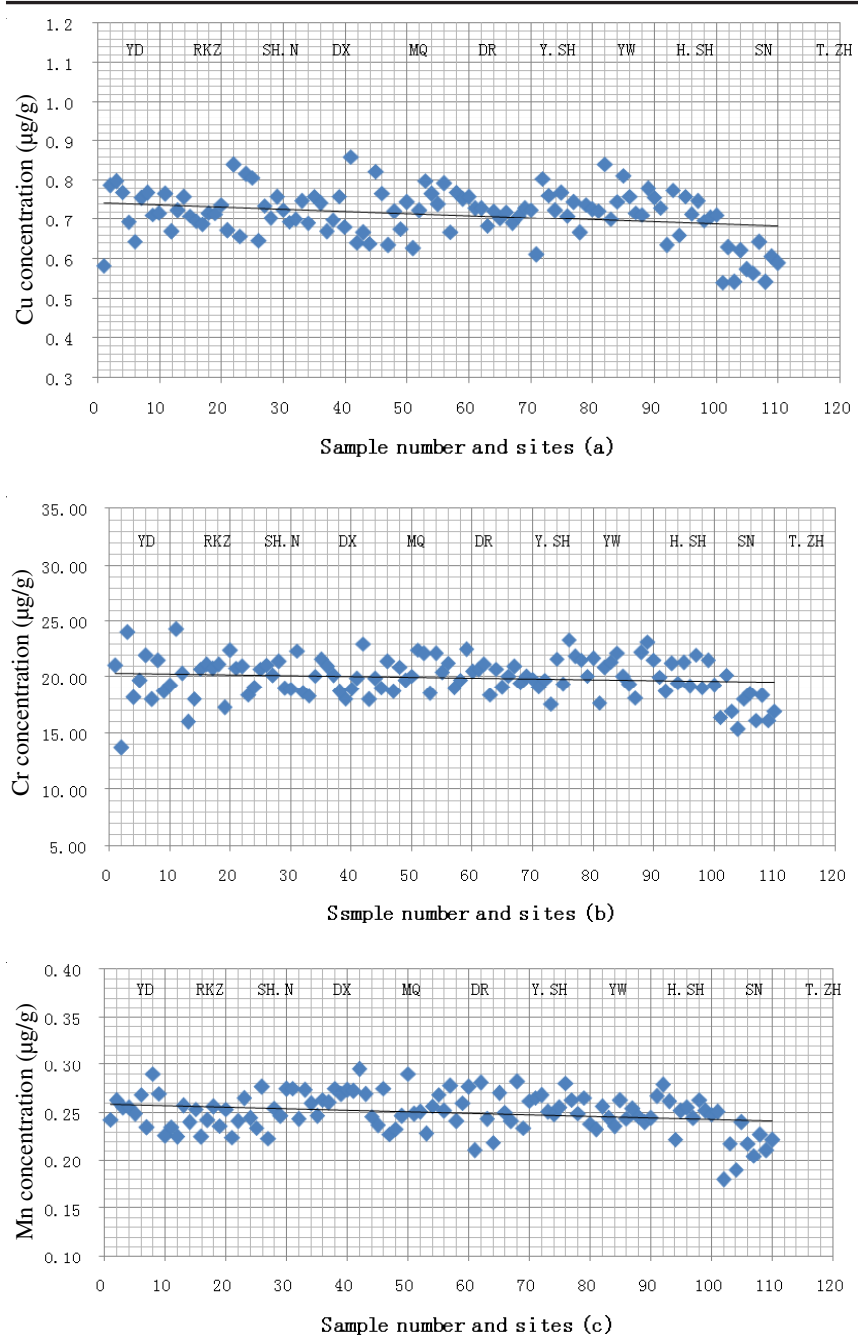

Fig. 2. Plasma $\mathrm{Cu}, \mathrm{Cr}, \mathrm{Mn}$ distribution of yak from 11 sites. Samples ordered in sequence with Yadong (YD), Rikeze (RKZ), Shannan (SH.N), Dangxiong (DX), Maqin (MQ), Dari (DR), Yushu (Y.SH), Yiwu (YW), Heshuo (H.SH), Sunan (SN) and Tianzhu (T.ZH)

TABLE-1

\begin{tabular}{lccc}
\multicolumn{4}{c}{ TABLE-1 } \\
\multicolumn{4}{c}{ CONCENTRATION OF TRACE ELEMENTS IN } \\
BLOOD OF YAK IN DIFFERENT REGIONS $(\mu \mathrm{g} / \mathrm{g})$ \\
\hline \multicolumn{1}{c}{ Places } & $\mathrm{Cu}$ & $\mathrm{Cr}$ & $\mathrm{Mn}$ \\
\hline Yadong & $0.723 \pm 0.068 \mathrm{a}$ & $19.617 \pm 2.793 \mathrm{ab}$ & $0.255 \pm 0.019 \mathrm{ab}$ \\
Rikeze & $0.717 \pm 0.031 \mathrm{a}$ & $20.217 \pm 2.471 \mathrm{~b}$ & $0.242 \pm 0.012 \mathrm{abc}$ \\
dangxiong & $0.714 \pm 0.035 \mathrm{a}$ & $19.789 \pm 2.19 \mathrm{ab}$ & $0.264 \pm 0.012 \mathrm{ab}$ \\
Shannan & $0.736 \pm 0.069 \mathrm{a}$ & $20.060 \pm 1.098 \mathrm{~b}$ & $0.248 \pm 0.019 \mathrm{ab}$ \\
Yushu & $0.714 \pm 0.017 \mathrm{a}$ & $20.047 \pm 0.879 \mathrm{~b}$ & $0.249 \pm 0.024 \mathrm{ab}$ \\
Maqin & $0.717 \pm 0.080 \mathrm{a}$ & $20.064 \pm 1.433 \mathrm{~b}$ & $0.259 \pm 0.024 \mathrm{ab}$ \\
Dari & $0.740 \pm 0.055 \mathrm{a}$ & $20.877 \pm 1.449 \mathrm{~b}$ & $0.256 \pm 0.015 \mathrm{ab}$ \\
Tianzhu & $0.585 \pm 0.038 \mathrm{~b}$ & $17.315 \pm 1.450 \mathrm{ac}$ & $0.216 \pm 0.021 \mathrm{c}$ \\
Sunan & $0.713 \pm 0.044 \mathrm{a}$ & $20.174 \pm 1.228 \mathrm{~b}$ & $0.254 \pm 0.015 \mathrm{ab}$ \\
Heshuo & $0.755 \pm 0.046 \mathrm{a}$ & $20.662 \pm 1.814 \mathrm{~b}$ & $0.246 \pm 0.009 \mathrm{ab}$ \\
Yiwu & $0.725 \pm 0.055 \mathrm{a}$ & $20.608 \pm 1.704 \mathrm{~b}$ & $0.258 \pm 0.012 \mathrm{ab}$ \\
\hline
\end{tabular}

Note: Different letters in the same row means significant difference between the treatments $(p<0.05)$, same letter in the same row means not significant difference between treatments $(p>0.05)$.

Copper status: The data in Table-1 showed that the concentration of plasma $\mathrm{Cu}$ were indistinctive among Rikeze, Dangxiong, Yushu, Maqin, Dari, Sunan, Heshuo, Yiwu, Yadong and Shannan $(p>0.05)$. But the plasma $\mathrm{Cu}$ of Tianzhu yaks were significantly lower than any other sites $(p<0.01)$.
Manganese status: concentration in Tianzhu site were significantly lower than Dangxiong, Yadong, Maqi, Dari, Yiwu, Sunan, Shannan and Yushu $(p<0.003)$, significantly lower than Heshuo $(p<0.013)$ and marginally lower than Rikeze ( $p$ $>0.065)$. The concentration of plasma Mn were similar among all sites $(p>0.393)$ except Tianzhu site.

Chromium status: Tianzhu site were most significantly lower than Dari, Yiwu and Heshuo $(p<0.002)$, significantly lower than Rikeze, Shannan, Maqin, Sunan and Yushu $(p<$ $0.0029)$, but no significantly lower $(p>0.089)$ than Yadong and Dangxiong.

Correlation analysis: Trace elements in the body of organisms are balanced when organisms are in normal living condition. The interaction mechanisms among trace elements can increase or decrease the absorption of some trace elements. For example, in study of the marine amphipod Corophiumvolutator exposed to heavy metal, it was found that when cadmium and zinc were added together, cadmium was less toxic and tissue concentrations were reduced ${ }^{17}$. So researching the correlation of trace elements is indispensable in both health protection and clinic $^{18-20}$. Some research comparing the correlation of some important trace elements in organism have been conducted in animaland aquatic. In experiment using cows, Patra et al. ${ }^{21}$, reported that the milk cobalt concentrations of lactating cows raised around different industrial units were significantly correlated $(\mathrm{r}=0.365, p<0.001)$ with cadmium level in milk and the highest milk cadmium $(>0.10-0.39 \mu \mathrm{g} /$ $\mathrm{mL})$ group had significantly $(p<0.05)$ increased milk cobalt.

In present study of correlation between copper and other trace elements in plasma from yaks, we found a significant positive correlations between plasma copper and plasma chromium $(r=0.282, p<0.003)$. Furthermore, the correlations between plasma copper and plasma manganese were also significant $(\mathrm{r}=0.254, p<0.007)$. This is consistent with findings reported by $\mathrm{Wu}$ et al. ${ }^{22}$ that the content of $\mathrm{Cu}$ was significantly correlated with $\mathrm{Mn}(\mathrm{r}=0.248, p<0.01)$ in hair in 1051 children.

As we mentioned above, the effects of supplying trace elements to animalin the area of production efficiency, enhancing the resistance of disease, are remarkable and a great deal of research have been reported. In contrast, there were few relevant researches in yak, most of it raised in the special Qinghai-Tibet Plateau chilliness altiplano ecosystem. A few studies were focused on the concentrations of trace elements in different part of yak which lived at the same area or on comparing the concentrations of trace elements in the body of yak with different breeds. Availability studies to the deficiency of trace element on chilliness altiplano have been examined most extensively in local critter' blood ${ }^{23-28}$. The result showed that trace element such as $\mathrm{Cu}, \mathrm{Cr}$ and $\mathrm{Mn}$ were deficiency in a certain extent or distributing imbalance.

The data of trace element concentrations we analyzed by ANOVA also showed that the concentrations of plasma $\mathrm{Cu}$ of yak from four province's 11 sites were lower than the critical levels reported by Wang et al. ${ }^{29}$ and Blood ${ }^{30}$. It is noticed that the concentration data of plasma $\mathrm{Cu}, \mathrm{Cr}$ and $\mathrm{Mn}$ from white yak producing area in Tianzhu (Gansu) were in the lowest level. Statistical analysis of plasma trace element showed that the plasma $\mathrm{Cu}$ were considered the most significant differences among the entire areas and that the plasma $\mathrm{Cr}$ were also 
significant different. While the plasma Mn were not significant different, the concentration of plasma $\mathrm{Cu}$ had a significant positive correlations with $\mathrm{Mn}$ and $\mathrm{Cr}$. This may indicate that the low concentration levels in plasma $\mathrm{Mn}$ and $\mathrm{Cr}$ in Tianzhu white yak might becaused by $\mathrm{Cu}$ deficiency.

Because of white yak's unique biological character and considerable economic benefits, a total of 307 yaks from the Tianzhu White, Jiulong, Maiwa and Datong breeds in China were genotyped at the $\kappa$-casein locus by Bai et al. ${ }^{31}$, to compare the dissimilarity of them using A PCR-single strand conformation polymorphism protocol developed in the their study. The occurrence of an allele $\mathrm{C}$ in the Tianzhu White breed was high with an allele frequency of 0.15 . However, allele $\mathrm{C}$ appears to be absent in the yaks from Jiulong, Maiwa and Datong breeds.

However, the distinct differences of trace elements concentration of yak blood plasma found in our study make us to think of this problem in another way. As we know that trace element copper plays an important role for organism's hair growth and it's absence or malfunction leads to the genetically inherited disorders ${ }^{32-34}$. Another study indicated that within the epidermis and hair follicles are melanin-containing melanosomes synthesized by melanocytes and transferred to surrounding keratinocytes whereas melanin synthesis requires the copper-containing enzyme tyrosinase which acts on tyrosine as its initial substrate. Albinism results when melanocytes of hair, skin and eyes either fail to synthesize melanin for as yet little under stood reasons ${ }^{35}$. Although many genes may influence skin and hair colour in yak as they do in other mammals such as the mouse, It may therefore be inferred that copper deficiency in Tianzhu yak' body are likely to contribute to change gene pairs during melanogenesis.

\section{Conclusion}

From this experiment we find that the trace element deficiency is a prevalent problem in chilliness altiplano where yak mainly live. Therefore, trace elements supplement is a necessary means to improve livestock fertility. Although we only studied limited samples, our research supplies a basic reference to farmers supplementing trace element to yak.

Because Tianzhu white yak does not grow on many parts of the world, white yak'hair, fuzz, cercus so much as oxtail is rare and expensive materials in foreign trade and attracts many farmers to raise white yak. Because trace elements were indispensable to animal's growth, the significant low level of plasma $\mathrm{Cu}$ in white yak deserves further study in the area of the physiological character and prepotency of white yak. Further research is also needed to determine effects of $\mathrm{Cu}$ concentration on hair and skin of white yak.

Naturaly, trace element deficiencies are common in ruminants. The mechanism governing the concentrations of trace element in yak's body is complicated and many factors such as environment, soil, riverhead, forage grass, atmosphere and interactions of trace elements all play a role in these variations. Therefore, further research is needed to be confirmed when supplementing trace element to yak is beneficial.

\section{ACKNOWLEDGEMENTS}

This investigation is from National Natural Science Foundation of China (No. 30970519) and The Ministry of Education "Hunhui Plan" (No. Z2010075).

\section{REFERENCES}

1. E.J. Underwood, Zinc metabolism, Academic Press, New York (1997).

2. M. Clauss, C. Lendl, P. Schramel and W.J. Streich, Veterinary J., 167, 302 (2004).

3. U.M. Cowgill, S.J. States and J.E. Marburger, Environ. Pollut. Series A Ecol. Biol., 22, 259 (1980).

4. J.R. Prohaska and M.L. Failla, Copper Immunity, Plenum Publishing, New York (1993).

5. D.G. Jones and N.F. Suttle, Res. Vet. Sci., 31, 151 (1981).

6. J.R. Stabel and J.W. Spears, Effect of Copper on Immune Function and Disease Resistance, Plenum Publishing, New York (1990).

7. G.P. Gengelbach, J.D. Ward, J.W. Spears and T.T. Brown Jr., Anim. Sci., 75, 1112 (1997).

8. T.C. Nguyen, Vet. Immunol. Immunopathol., 5, 237 (1984).

9. D.P. Hutcheson, Nutritional Factors Affecting Immune Response in Cattle. Proc. of the Nutritional Aspects of Managing Feeder Cattle Symposium, Plains Nutrition Council (1989).

10. S.C. Guo, P. Savolainen, J.P. Su, Q. Zhang, D.L. Qi, J. Zhou, Y. Zhong, X.Q. Zhao and J.Q. Liu, BMC Evolutionary Biol., 6, 73 (2006).

11. M.J. Ji, C. Pu and Y. Dawa, Acta Veter. Zoo Technica Sin., 34, 368 (2003).

12. G.X. Zhang, W.S. Chen, M. Xue, Z.G. Wang, H. Chang, X. Han, X.J. Liao and D.L. Wang, J. Genet. Genomics, 35, 233 (2008).

13. L.R. McDowell, Minerals in Animal and Human Nutrition, Academic Press, London (1992)

14. J. Lee, D.G. Masters, C.L. White, N.D. Grace and G.J. Judson, Agric. Res., 50, 1341 (1999).

15. X.-Y. Shen, Agric. Sci. China, 8, 1000 (2009).

16. X. Wang, J. Zhou, P.S. Tong and X.Y. Mao, J. Dairy Sci., 94, 2731 (2011).

17. L. Bat, D. Raffaelli and I.L. Marr, J. Exp. Marine Biol. Ecol., 223, 167 (1998).

18. Z.-Y. Yu and Z. Hou, Microelement with Ailment Diagnose and Therapy, People's Medical Publishing House, Beijing (2001).

19. P. Bermejo-Barrera, A. Moreda-Piñeiro, J. Moreda-Piñeiro, A. BermejoBarrera and A.M. Bermejo-Barrera, J. Forensic Sci., 44, 270 (1999).

20. U. Majewska, J. Braziewicz, D. Banas', A. Kubala-Kukus', S. Gózdz,M. Pajek, J. Smok and A. Urbaniak, Biol. Trace Elem. Res., 60, 91 (1997).

21. R.C. Patra, D. Swarup, P. Kumar, D. Nandi, R. Naresh and S.L. Ali, Sci. Total Environ., 404, 36 (2008).

22. D.-S. Wu, Z.-A. Tian, X.-Y. Chen and G.-X. Lun, Trace Elem. Sci., 9, 43 (2002).

23. Qi Zhi-Ming, Ma Qing-De et al., Chin. Qinghai J. Aminal Veterinary Sci., 35, 9 (2005).

24. Y-X. Sun and C.-J. Zhang, Chin. J. Veterinary Sci. Technol., 30, 30 (2000).

25. Y.-L. Wang, R.-L. Yang and G.-R. Yin, China Agriculture Press, Beijing, pp. 95-117 (1988).

26. Y.-Y. Cheng and D.-L. Wang, J. Preventive Midic. Chin. Peoples Liberat. Army, 12, 337 (1994).

27. L.-B. Yang and Y.-R. Suo, Trace Elem. Sci., 11, 35 (2004).

28. C.-H. Li, Heilongjiang Animal Sci. Veterinary Med., 9, 18 (2001).

29. Z.-Y. Wang, G.-X. Cao and Z.-C. Hu, Ailment of Micoelement Metabolize, Shanghai Scientific Technical Publishers, Shanghai (1995).

30. D.C. Blood, VeterinaryMedicine, Bailliere, Tin-dall, London, edn. 7, pp. 1156-1202 (1998).

31. W.L. Bai, R.H. Yin, S.J. Zhao, Y.C. Zheng, J.C. Zhong and Z.H. Zhao, J. Dairy Sci., 91, 1204 (2008).

32. A.W. Franzmann, A. Flynn and P.D. Arneson, Comp. Biochem. Physiol. A: Physiol., 57, 299 (1977).

33. R.D. Hoeldtke, S.T. Cavanaugh, J.D. Hughes, K. Mattis-Graves, E. Hobnell and W.D. Grover, Pediatric Neurol., 4, 23 (1988).

34. S. La Fontaine and J.F.B. Mercer, Arch. Biochem. Biophys., 463, 149 (2007).

35. W.C. Quevedo Jr., T.B. Fitzpatrick and K. Jimbow, J. Human Evolution, 14, 43 (1985) 